\title{
La Virgen con Niño y ángeles músicos. Connotaciones sexuadas en el imaginario musical medieval ${ }^{1}$
}

\author{
The Virgin with Child and Musician Angels. \\ Sexual connotations in medieval musical imaginary
}

\author{
Josemi LOREnZo ArRIBAS \\ Investigador independiente \\ josemi20@hotmail.com \\ http://orcid.org/0000-0002-9412-8501
}

Fecha de recepción: 20/01/2021

Fecha de aceptación: 16/02/2021

\section{RESUMEN}

La dicotomía "cuerpo/mente" es una antigua taxonomía tradicional utilizada por el patriarcado para jerarquizar a los seres humanos. En el campo de la música, este emparejamiento se trasladó a la división entre instrumentos de cuerdas e instrumentos de viento. La Edad Media lo resignificó a través del iconograma de la Virgen con Niño rodeada por ángeles tañendo instrumentos musicales, en su mayor parte de "música baja". Hay razones de naturaleza bióloga, fisiológica, mítico-existencial, simbólica, musical y antropológica que justifican esta división arbitraria aplicada a las capacidades musicales de varones y mujeres. Tal vez su primera manifestación iconográfica se encuentra en una portada decorada (siglo XIII) del monasterio de Santa María de Carracedo (León).

Palabras clave: Música medieval, ángeles músicos, Dormición, Política sexual Topónimos: Carracedo (León), Bierzo

Periodo: Siglo XIII

\section{ABSTRACT}

The "body/mind" dichotomy is an old traditional taxonomy employed by the patriarchy to prioritise human beings. In the musical field, this pairing was transferred to the division between string and wind instruments. The Middle Ages resignified this through the iconography of the Virgin Mary with Child surrounded by angels playing musical instruments, mostly "low music" or soft music. There are reasons of a biological, physiological, mythical-existential, symbolic, musical and anthropological nature that justify this arbitrary division applied to the musical capacities of men and women. Its first

1 Presenté una primera versión de este texto ("Flesh, strings and feminine body in medieval musical thought, with a back-ground of music angels") en Performa '11. Encontros de investigação em Performance, Universidade de Aveiro (Portugal), 2011. 
iconographical manifestation can be perhaps be found in a decorated portico ( $13^{\text {th }}$ century) of the Monastery of Santa Maria de Carracedo, in Leon (Spain).

Key words: medieval music, musician angels, dormition, sexual politics

Toponyms: Carracedo (León), Bierzo

Period: 13th Century

\section{INTRODUCCIÓN}

Este artículo analiza, a la luz de la Historia de las Mujeres, el iconograma Virgen con ángeles músicos, llamado a tener larga vida en la tradición cristiana desde su aparición en el siglo XIII, a fin de analizar hasta qué punto la práctica musical real influyó en su definición, particularmente en el instrumentario puesto en manos de los seres alados. Además, se propone una temprana representación hispana como precedente de las que habrán de venir.

El Antiguo Testamento refleja la alegría en forma de sonido instrumental2 ${ }^{2}$ y los Evangelios apócrifos la continúan. No encontró el mismo entusiasmo en el Nuevo Testamento ni en la primera tratadística, pues los Padres de la iglesia fueron opuestos a los instrumentos musicales por la asociación a lo pagano que conllevaban ${ }^{3}$. Las escenas de danza fueron peyorativamente connotadas a partir de la bíblica danza de Salomé 4 . Las danzarinas, "saltatrices in modum filiae Herodiadis", responsables de ludos turpes, quedaron bajo el incómodo marco de este antimodelo ${ }^{5}$. Por el contrario, Miriam y sus compañeras (Mariae mulieres), otras danzantes judías que bailaron, en este caso en un contexto positivo, apenas fueron representadas. La carencia de modelos de mujeres "con voz cantante" en los textos neotestamentarios fue casi total, reducida al discreto canto del Magnificat por parte de María (Lucas 1, 46-55) con ocasión de la visita a su prima Isabel, que no tuvo traducción iconográfica. Las mujeres, en definitiva, no salieron bien paradas por la ausencia de modelos.

El imaginario cristiano medieval de los primeros siglos reducirá la representación plástica de la música a la escatología. Además de los Veinticuatro Ancianos del Apocalipsis (y de algún ángel con olifante, para anunciar plagas), y del Rey David como músico (escena repetida por la popularidad del salterio, pues se le hacía autor de los salmos), será el coro de los ángeles que proclaman eternamente la gloria de Dios el resquicio iconográfico donde la música tendrá presencia de pleno derecho. Ese coro se compone de ángeles cantores,

2 Entre los pasajes bíblicos en los que se encuentra este binomio: Job 21, 12; Jue. 11, 34; I Sam. 18, 6; II Sam. 6, 5 y 15; I Crón. 15, 16-28; I Crón. 16, 5-6; I Crón. 25, 1-8; Neh. 12; I Mac. 4, 54; I Mac. 13, 51; Ecl. 2, 8; Eclo. 40, 20-1; Eclo. 40, 1; I Reyes 10, 12; Am. 6, 5; Sal. 68, 26; Is. 5, 12; Esd. 3, 10; Salmo 33, 2-3, Salmo 81, 3-4; Salmo 98, 5-6; Salmo 144, 9; Salmo 147, 7; Salmo 149, 3; Salmo 150, 3-5...

3 Los Hechos de Tomás sitúan dentro del templo a "virgines cum liris canentes, alii cum tibiis, alii cum tympanis, alii cum vitulis atque turibulis" (cit. F. J. Basurco, El canto cristiano en la tradición primitiva, Madrid, Ediciones Marova, 1966, pp. 143-144).

4 Generalmente uno o más juglares tañen para que la hija de Herodías baile, pero en la pintura gótica a veces ella misma se representa tañendo, acompañando su propia danza.

5 Cita extraída de los Capitula ( $n^{\circ}$ XVII) de Walter de Orleáns (ca. 858): "rusticis cantilenis caveant nec saltatrices in modum filiae Herodiadis coram se turpes facere ludos permittant" (cit. en H. Waddell, The Wandering Scholars, London, Constable, $7^{\mathrm{a}}$ ed., 1966, p. 275). 
pero también de instrumentistas ${ }^{6}$. De no haber sido por ellos no dispondríamos del inmenso caudal de representaciones bajomedievales que disfrutamos.

El camino seguido por los emisarios alados hasta que se hicieron músicos no fue rápido. La primera mención a ángeles que cantan se produce en el Evangelio del Pseudo Mateo (siglo VI), cuando algunos pastores afirmaban haber visto ángeles "diciendo himnos"7. También en los Apócrifos pasionistas hay una segunda mención en la escena de la Resurrección de Cristo. Los ángeles al principio cantan (o "dicen", recitan, ¿cantilan?), no tañen. Desde el punto de vista doctrinal los ángeles músicos reaparecen en la segunda mitad del siglo XII con la recepción de los textos de Dionisio Aeropagita y con un tratado perdido de Ramón Llull ${ }^{8}$, y se codificará en el siglo siguiente a través de la Leyenda Dorada del dominico Santiago de la Vorágine. A partir de entonces, tales músicos pasarán a la iconografía, y los instrumentos musicales serán su símbolo parlante, pues son evidentes las dificultades de representar el canto, la sola interpretación vocal, sin acudir al atributo iconográfico del instrumento musical ${ }^{9}$.

No todos los instrumentos musicales estuvieron al alcance de todo el mundo, al menos normativamente. Los mandatos culturales "generizaron" también la práctica instrumental, consiguiendo asociar ciertos tipos de instrumentos a cada uno de los sexos. No es aleatoria, por lo tanto, la práctica inexistencia de representaciones de mujeres reales, sin recurrir al trasunto mitológico o trascendente, tañendo un cuerno o un orlo, por ejemplo. Así pues, el uso que hicieron de ellos tuvo diferentes connotaciones, principalmente evaluables a partir de la condición social de dichas mujeres. Las mujeres de clases altas emplearon la música, y en concreto la habilidad instrumental, como un embellecimiento, mientras las de las clases más desfavorecidas hicieron de esta cualidad una profesión.

Desde el nacimiento de la música instrumental como tal en Europa, desligada del uso litúrgico, el instrumentario se dividió, en la práctica, en dos categorías bien definidas: los que producían música alta y los que tañían música baja. La diferencia se establecía conjugando los parámetros volumen y timbre de cada instrumento, más que por tesitura, pues coexistieron en ambos grupos instrumentos agudos y graves. Los más ruidosos formaban parte de los altos y viceversa ${ }^{10}$. La diferencia no se estableció únicamente basándose en cuestiones sonoras, sino que también los teólogos participaron de la clasificación, contraponiendo la música angelical a la demoníaca, trasponiendo en el trasunto escatológico el simbolismo del nivel, o mistificando la significación musical con otras socioeconómicas, etcétera ${ }^{11}$. De este

6 Para el simbolismo instrumental en la Patrística: J. Gelineau, Canto y música en el culto cristiano, Madrid, Juan Flors, editor, 1967, pp. 174 ss.

7 Evangelio del Pseudo-Mateo, XIII.6 (A. de Santos Otero (ed.), Los Evangelios apócrifos, Madrid, Biblioteca de Autores Cristianos, 2005, p. 91), si bien en esta traducción se traduce como "cantando himnos".

8 M. C. Rodríguez Suso, "The Nursing Madonna with Musical Angels in the Iconography", Music in Art, 12/1 (1987), p. 17; M. D. Barral Rivadulla, "Ángeles y demonios, sus iconografías en el arte medieval", Cuadernos del CEMYR, 11 (2003), pp. 211-235.

9 J. Lorenzo Arribas, "La voz femenina, un tabú cultural. Mujeres, música y representaciones en el Románico", en Féminas: el protagonismo de la mujer en los siglos del románico. Aguilar de Campoo, Fundación Santa María la Real, 2020. pp. 189-225.

10 R. Andrés, "Anotaciones para un prólogo", [Prólogo a] Los luthiers españoles (de R. Pinto Comas). Barcelona, 1988: p. 23; vid. E. A. Bowles, La pratique musicale au Moyen Age. Musical Performance in the Late Middle Ages, Géneve, Minkoff \& Lattès, 1983, pp. 43-99, para representaciones iconográficas de instrumentos de música alta que, generalmente, estaban puestos al servicio heráldico para las grandes ocasiones (coronaciones, fiestas, bodas, torneos...). Para instrumentario bajo, cuya ejecución se producía muchas veces en espacios cerrados (cenas, danzas cortesanas, hagiografías...): Ibidem, pp. 101-145.

11 W. Salmen, "The Social Status of the Musician in the Middle Ages", en W. Salmen (ed.), The Social Status of the Professional Musician from the Middle Ages to the 19th Century, New York, Pendragon Press, 1983, p. 
modo, los instrumentos altos, compuestos principalmente por lo que hoy denominaríamos las familias de viento-metal, se consideraron más excelsos que los bajos ${ }^{12}$. Entre los catalogados como música baja encontramos a los cordófonos, las flautas de pico y el órgano $^{13}$. En realidad, se actualizaba bajo nuevas nomenclaturas la vieja dicotomía griega ${ }^{14}$. Lo que antes fue la polémica aulética-citarística queda ahora conceptuada como música alta-música baja. Ya en la propia denominación opera una jerarquización, pues actúa la universal simbología del nivel, según la cual, y por definición, lo alto es más importante que lo bajo. Así, la música baja comienza en desventaja a la hora de la pugna simbólica. Aunque la apariencia de muchas de las interpretaciones expuestas sea erudita, no debemos perder de vista la idéntica consideración que realiza la llamada cultura popular, frecuentemente origen último de la anterior, en continua interacción y contaminación, y, en ocasiones, de imposible deslinde.

Esta simbología instrumental, que es mucho más extensa y compleja, la hemos incrementado con una asociación iconográfico-conceptual que provocó o reforzó el binomio al que nos venimos refiriendo. A mi entender, forma una de las constantes y de los núcleos teóricos más potentes de la música occidental analizada desde una perspectiva de género: la relación entre los instrumentos de música baja y las mujeres. Según coincide la historiografía, la iconografía de los ángeles músicos nace hacia 1300, y desde Italia el motivo se expande durante el Trecento ${ }^{15}$ hasta constituir un verdadero continuum de significado, actualizado constantemente.

\section{RAZONES DE UNA AUDIOTOPÍA, CUANDO LOS ÁNGELES MÚSICOS SONORIZAN ESPACIOS MARIANOS}

En la Plena Edad Media nace, pues, una novedosa audiotopía, el concierto angélico. Con el tiempo, los ángeles músicos aparecerán en las escenas del Juicio Final, marginalmente en el Nacimiento de Cristo (los pastores monopolizarán casi esta labor), y, sobre todo, en contexto mariano ${ }^{16}$ : en el Tránsito, la Asunción y la Coronación de la Virgen, sin excluir

8; M. J. Kartomi, On Concepts and Classifications of Musical Instruments, Chicago and London, The University of Chicago Press, 1990, p. 143.

12 Salmen, "The Social Status...", pp. 8-12.

13 Pudiera parecer contradictorio que un instrumento como este perteneciera a la música baja, lo que se comprende conociendo las dimensiones y posibilidades de los órganos medievales. Hasta la Plena Edad Media se empleó el órgano portativo, instrumento transportable que no requería de ninguna otra persona para accionar su único fuelle, pues sus pequeñas dimensiones permitían tocar el teclado con una mano y con la otra insuflar el aire, mientras un correaje lo sujetaba al cuerpo. Aunque algún estudioso, sin explicar por qué, lo sitúa entre los "altos instrumentos" (W. Salmen, "The Social Status...", p. 13), su verdadero lugar se encontraba entre los bajos, dada su cualidad tímbrica y su relativo volumen (E. Winternitz, Musical Instruments and Their Symbolism in Western Art, New Haven and London, Yale University Press, 1979, p. 146; Andrés, "Anotaciones...", p. 22).

14 E. Fubini, La estética..., p. 42.

15 K. Meyer-Baer, Der chorische Gesang der Frauen mit besonderer Bezugnahme seiner Betätigung auf geistlichem Gebeit, Leipzig, Breitkopf und Härtel, 1917) afirmaba que en el siglo XIII todavía no existían ángeles músicos (cit. en Rodríguez Suso, "Un ejemplo de iconología musical...", p. 14, nota 32). Vid. también J. y G. Montagu, Minstrels and Angels Carvings of Musicians in Medieval English Churches, Berkeley, Fallen Lean Press, 1998; F. Ghisi, "Angeli musicanti in una tavola attribuita al Giottino nel Museo del Bargello di Firenze", en F. Gallo (ed.), L'ars nova italiana del Trecento. Certaldo, Centro di Studi sull'Ars Nova italiana del Trecento, 1968, p. 92, nota 1.

16 En mi tesis doctoral catalogué un total de 226 obras entre los siglos XIII y XVI, correspondientes todas a representaciones iconográficas de María con ángeles músicos. La proporción de cordófonos (más órganos) superaba la relación 7:1, sin incluir otros instrumentos de música baja, ni la música vocal, ni otras consideraciones que harían mucho más abrumadora la proporción, cercana al noventa por ciento (J. Lorenzo 
la Anunciación ${ }^{17}$. Pero en el inicio fue la "Virgen con Niño" la que apareció identificada por la sonoridad musical. A finales del siglo XIV, María se presentará rodeada de ángeles instrumentistas por doquier. No es Cristo, ni Dios Padre, sino una mujer, modelo y espejo de todas las demás, quien se rodea de música. Este modelo pervivió muchos siglos después sin apenas variaciones. (Figuras 1 y 2)

Figura 1. Virgen con ángeles músicos, de Pere Serra, tabla que formaba parte de un retablo pintado hacia 1390 para la catedral de Tortosa (Tarragona). Los seis ángeles tañen instrumentos propios de la "música baja"

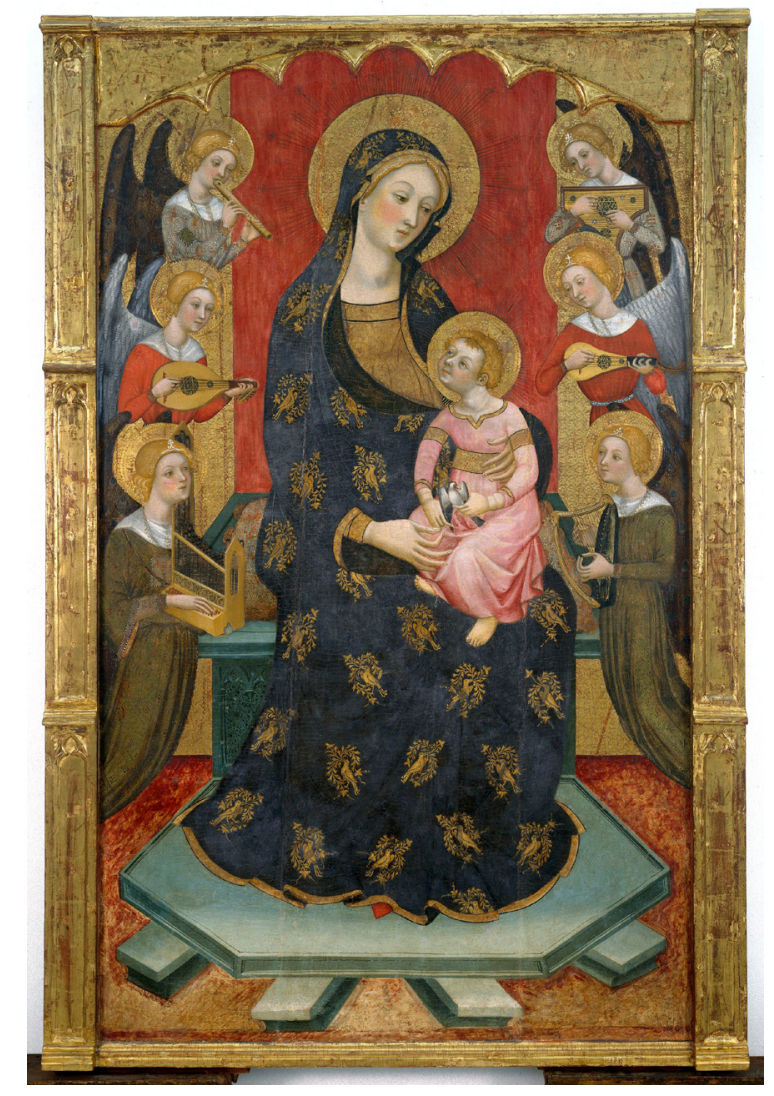

Fuente: Museu Nacional d'Art de Catalunya. Disponible en https://www.museunacional.cat/es/colleccio/ virgen-de-los-angeles/pere-serra/003950-000 [Consulta: 10-02-2021]

Arribas, Las mujeres y la música en la Edad Media europea: relaciones y significados, Madrid, Universidad Complutense, Tesis doctoral inédita, 2004, pp. 713-739 y 845-857).

17 J. Ballester i Gibert, "Retablos tardomedievales con ángeles músicos procedentes del antiguo Reino de Aragón. Catálogo", Revista de Musicología, 12/1 (1990), pp. 123-201; J. Ballester i Gibert, "Music in the Sixteenth-Century Catalan Painting", Music in Art (2006), pp. 132-142. C. Perpiñá García, "Los ángeles músicos. Estudio de los tipos iconográficos de la narración evangélica", Anales de Historia del Arte (vol. extraord., 2011), pp. 397-411; C. Perpiñá García, "Los ángeles músicos en el tipo iconográfico de la Anunciación", en Emblemática trascendente: hermenéutica de la imagen, iconología del texto. Pamplona, Universidad de Navarra, 2011, pp. 673-687; "Música angélica en la imagen mariana. Un discurso visual sobre la esperanza de salvación", Acta Artis. Estudis d'Art Modern, 1 (2013), pp. 29-49; J. M. Salvador González y C. Perpiñá García, "Exaltata super choros angelorum: Musical Elements in the Iconography of the Coronation of the Virgin in the Italian Trecento Painting", Music in Art, 39/1-2 (2014), pp. 61-86. En Bizancio, los ángeles músicos en escenas marianas no predatan a los occidentales (A. Gillette, "The Music of Angels in Byzantine and Post-Byzantine Art", Peregrinations. Journal of Medieval Art and Architecture, 6/4, (2018), pp. 26-78); A. Gillette, "Depicting the Sound of Silence: Angels' Music and Angelization in Medieval Sacred Art", Imago Musicae, 27/28 (2014/2015), pp. 95-125. 
Hayrazones paraesa preferencia en la asociación mujeres/músicabaja(particularmente cordófonos), que resumo muy sintéticamente desde seis argumentos que forman una red cultural de significados que se interrelacionan y que, como se dijo, actúan tanto desde la tradición simbólica popular como desde la culta.

\subsection{Argumento biológico o biologicista}

Los instrumentos de viento se definen por la columna de aire que los alimenta. Los de cuerda emiten su sonido a partir de estas que se confeccionaban con tripa de animal, siendo por tanto de carne. Con esto ya tenemos dos elementos dicotómicos que el patriarcado ha instrumentalizado constantemente para minusvalorar a las mujeres: la oposición entre lo etéreo — principio espiritual_ y lo tangible — principio material—, par que se presenta bajo distintas fórmulas. Las mujeres se vinculan, de esta manera, al principio carnal, vía cuerdas, con el que la mentalidad patriarcal las identifica.

La morfología de los instrumentos musicales, su propia forma, también ha reforzado esta consideración, y no solo en la cultura occidental. El musicólogo alemán Curt Sachs ya puso de manifiesto en la década de los cuarenta del siglo XX cómo la flauta era considerada un instrumento fálico por su forma, hecho que se documenta en las sociedades actuales que llamamos tradicionales, y que también pervive en las jergas modernas occidentales ${ }^{18}$. Por el contrario, los instrumentos de cuerda pulsada o punteada (también los panderos, por su parche carnal) eran identificados con el sexo femenino ${ }^{19}$, a lo que coadyuva también su estructura morfológica, con su boca o tarraja como elemento central y la preponderancia de la línea curva ${ }^{20}$. Llevando esta línea interpretativa al plano de la metáfora, las cuerdas son mucho menos estables en cuanto a su afinación que los aerófonos o ciertos idiófonos con los cuales se suele representar a los míticos inventores de la música, como las campanas, que no se desafinan. Los cordófonos (como las mujeres para el patriarcado) precisan de una referencia externa para asegurar su buen comportamiento en conjunto (ensemble instrumental, es decir, la sociedad), y poder tañer afinados junto a los otros instrumentos que tienen la fiabilidad de la música teórica, predio exclusivo varonil ${ }^{21}$.

18 C. Sachs, Historia universal de los instrumentos musicales, Buenos Aires, Ediciones Centurión, 1947, pp. 43-44.

19 En ciertas zonas del Piamonte al órgano sexual femenino se le denomina guitarrita (M. Franco-Lao, Música bruja. La mujer en la Música, Barcelona, Icaria, 1980, p. 34). Marius Schneider, en sus peculiares (y desfasadas) teorías sexúa hasta las notas musicales y, según él, el sonido re sería masculino y el sonido la, femenino (M. Schneider, El origen musical de los animales-símbolos en la mitología y la escultura antiguas, Madrid, CSIC, 1946, p. 227), dice que las cuerdas "unidas a un instrumento de música con formas femeninas expresan un factor erótico. Corrientemente el cuerpo del laúd se compara al de la mujer (tierra), aunque sea claramente masculino su elemento principal, a saber, las cuerdas" (Ibidem, p. 129).

20 Figuras mitológicas femeninas remataron los clavijeros de las violas da gamba desde principios del siglo XVII, o en la parte delantera del arpa irlandesa (B. Boydell, "Female Figures on Irish and European Harps", The Galpin Society Journal, 50, (1997), pp. 306ss). También se aducen motivaciones políticas al representar a la Niké en el arpa irlandesa, instrumento nacional de este país, que simbolizaría el control de Inglaterra sobre Irlanda. Encontramos en este país representaciones de mujeres tañendo arpas al menos desde 1376 (A. Buckley, "Musical Instruments in Ireland from the Ninth to the Fourteen Centuries. A review of the Organological Evidence", en G. Gillen y H. White (eds.), Irish Musical Studies, vol. 1: 'Musicology in Ireland', Dublin, Irish Academic Press, 1990, lám. XVII).

21 A pesar de la también clásica iconografía de Pitágoras descubriendo la afinación a través del monocordio, instrumento que consta de una cuerda sobre un bastidor a partir de la cual el sabio griego va descubriendo las proporciones entre los distintos intervalos musicales golpeando con pequeños martillos. Es una opinión unánime el uso del monocordio como instrumento teórico únicamente. 


\subsection{Argumento mítico-existencial}

El Génesis bíblico contribuyó a perfilar más la naturaleza de los elementos que se asocian a ambos principios, otorgando a la distinción convencional estatuto de trascendencia. Según este libro fundacional, Dios creó a Adán mediante el soplo, infundiendo Su hálito (Génesis 2, 7). Posteriormente, el evangelista Juan (1, 1-3) afirmó que el Verbo, la Palabra entendida en cuanto flatus vocis, era Dios mismo. Eva procede por derivación de un principio carnal, la costilla del primer hombre; nace de la carne, como las cuerdas de los instrumentos musicales. Por otro lado, si la forma informa de la sustancia, como se creía en la Edad Media, la morfología de los instrumentos musicales (fálicos los de viento, redondeados los cordófonos) también pudo reforzar esta consideración. Ello no empece la metáfora de Venancio Fortunato, que hizo de María un tubo sonoro ${ }^{22}$ (no deja de ser un recipiente pasivo) por el que pasa y resuena la voz del Espíritu, sin mancillar, como el sonido, para justificar la versión de la inmaculada concepción de Cristo a través del oído ("aure Virgo concipit"). Es decir, una interpretación que se puede llamar acústica frente a la visual, mucho más empleada ("sicut solis radius"). Ese mismo oído, protagonista de la concepción de su Hijo sin concurso humano, será regalado por la música que lo alabará eternamente. En resumen, el doble silogismo queda expresado así:

\section{CORDÓFONOS - CARNE - MUJERES \\ AERÓFONOS - LOGOS - VARONES}

Todo argumento es reversible cuando se trata de polemizar. En el contexto del resucitado debate Apolo/Marsias de la España del siglo XVI, el vihuelista Luis de Narváez se valía de esta asimilación carnal para hacer de su instrumento, frente al resto, que cumplen el papel de referentes polémicos silenciados, el principal de la jerarquía: "...esta es una de las mayores excelencias que la vihuela tiene sobre todos los ynstrumentos allende: que es más perfecta por la semejança y conformidad que el sonido de la cuerda tiene con el sentido humano por ser de carne las cuerdas de la vihuela"23.

\subsection{Argumento fisiológico}

Sin haber encontrado una fuente documental que explícitamente soporte esta deducción, creemos que viene también a yuxtaponerse al resto de interpretaciones. Las teorías médicas medievales hacían de los humores corporales el eje gravitacional que definía no sólo el estado de salud, sino también los caracteres de las personas; hasta el mismo sexo de nacimiento tenía su explicación en tales fluidos. La consideración tradicional, hipocrática, consideraba que las mujeres eran húmedas y frías, frente a los varones secos y calientes, y puede estar en relación con la prohibición no explicitada de tañer aerófonos, ya que en esa codificación dicotómica el aire se aviene mejor con esa humedad y frialdad propia de la biología femenina, y la tierra con las características masculinas. El corolario de este argumento es que tañer aerófonos supone añadir aire al aire, reforzar ese principio femenino que se trata de domesticar con la cultura.

Una línea argumentativa más débil, aunque posiblemente eficaz, da por supuesto que las mujeres no poseen suficiente fuerza en los hombros para transportar ciertos instrumentos, por lo común de la familia que hoy llamamos viento-metal ${ }^{24}$. Finalmente,

22 Rodríguez Suso, “Un ejemplo de iconología musical...", p. 25.

23 L. de Narváez, Los seys libros del Delphín de música, Valladolid, 1538, en la última página del Prólogo.

24 E. Rieger, “¿‘'Dolce semplice’? El papel de las mujeres en la música”, en G. Ecker (ed.), Estética feminista, Barcelona, Icaria, 1986, p. 176; Franco-Lao, Música bruja..., p. 33. 
otras teorías cuestionan también la necesaria potencia pulmonar para tañer instrumentos de viento que precisen de una columna de aire potente para accionarlos. Las mujeres, en cuanto sexo débil, fueron poco aptas para este tipo de exigencias.

\subsection{Argumento simbólico}

El patriarcado siempre ha puesto énfasis en el control de la actitud del cuerpo femenino, más cuando este se exhibe en público. La actividad musical implica una acción corporal, obvia para danzar, necesaria para cantar y precisa para tañer. Así, habrá instrumentos que no se recomienden a las mujeres porque la acción sobre ellos implica una serie de actitudes con el cuerpo (posición, gestos) que se consideran impropias.

La confirmación se actualizó a mediados del siglo XVI. El vihuelista Alonso de Mudarra recogió, no sin cierto sentido del humor, el testigo de la crítica gestual que ya los griegos habían enunciado, y puso en boca de Alcibíades: "que tenía por mejor la música de la vihuela que la de las flautas, porque con la vihuela no se pierde la habla ni la figura del rostro como con las flautas la pierden los que las tañen, y esto en tanta manera que apenas son de sus amigos, quando están tañiendo, conocidos"25. En las mismas fechas, Hernando de Cabezón extendió la misma explicación al órgano, instrumento habitual en la iconografía mariana con ángeles músicos, ya que con él, según, no se descomponía la "voz, gesto o meneo mientras tañe, sino que está sentado y compuesto con sosiego, auctoridad y servicio..."26.

\subsection{Argumento musical}

El instrumentario bajo, de escaso volumen sonoro, está pensado para el espacio doméstico, donde alcanza sus cotas de excelencia. De ahí derivará la chanson de toile o, acorde con el decir de Barberino, esa música doméstica propia para acompañar "il canto basso, chiamato camerale" (la después denominada musica da camera). El instrumentario masculino, sensu contrario, se identificó con el propio de la música alta, ideal para el espacio público por su timbre, potencia y naturaleza. La música conmemorativa, cívica, heráldica, fue monopolizada por los varones. En feliz expresión de Rodríguez Suso, los instrumentistas altos eran, más que músicos, "guerreros sonoros"27. No había espacio para las mujeres.

Además, los instrumentos bajos durante la Edad Media tuvieron una función más acompañante que solista. En realidad toda la música instrumental propiamente medieval estuvo supeditada al canto, verdadero protagonista musical, pero, con el desarrollo de la polifonía, el instrumentario susceptible de autonomía musical quedó reducido a la cuerda pulsada y al órgano, que aún así hasta el siglo XV no conocieron repertorio propio. Las características de los instrumentos monódicos por naturaleza (todos los aerófonos) les hacían conservar su protagonismo tímbrico y su individualidad dentro del conjunto instrumental. No así los cordófonos, que se mantenían en segundo plano (el bajo continuo del Barroco), acompañando y ofreciendo el entramado modal o, después, contrapuntístico, pero sin un protagonismo evidente, dada su limitación tímbrica. Esta función acompañante pudo ser

25 A. Mudarra, Tres libros de música en cifras para vihuela. Sevilla, Juan de León, 1546, "Epístola la muy magnífico señor don Luys Çapata". La posición que se adopta al tañer los instrumentos de cuerda tienen un carácter femenino (Schneider, El origen musical..., p. 129).

26 A. de Cabezón, Obras de Música para tecla, arpa y vihuela... recopiladas y puestas en cifra por Hernando de Cabezón su hijo (Madrid 1578), vol. I. Higinio Anglés (ed.), Barcelona, CSIC, 1982, p. 21. De modo similar se manifestaba Castiglione en 1528 (A. Pugh, Women in Music, Great Britain, Cambridge University Press, 1991, p. 7). Más tarde llegarán razones para justificar que las mujeres no tañan violoncelos por la indecorosa visión de un instrumento entre las piernas abiertas, u otros prejuicios, vigentes hasta nuestros días.

27 Rodríguez Suso, “Un ejemplo de iconología musical...", p. 28. 
una vía que permitiera el acceso de ciertas mujeres a este instrumentario, más propio de su función gregaria en la mentalidad patriarcal, ostentando los varones la exclusividad a la hora de tañer instrumentos altos que individualizaban su línea melódica. Una vez que los instrumentos polifónicos como las violas (de mano o arco) o el laúd se independizan y adquieren un repertorio solista, la ejecución ya profesionalizada del instrumento quedó en manos masculinas, repitiendo otra constante en la historia occidental: la prohibición a las mujeres de ciertas prácticas que antes sí realizaban cuando estas se profesionalizan.

Figura 2. Maestro de Pottendorf. Virgen con Niño entre ángeles, con santa Dorotea y santa Bárbara (ca. 1465)

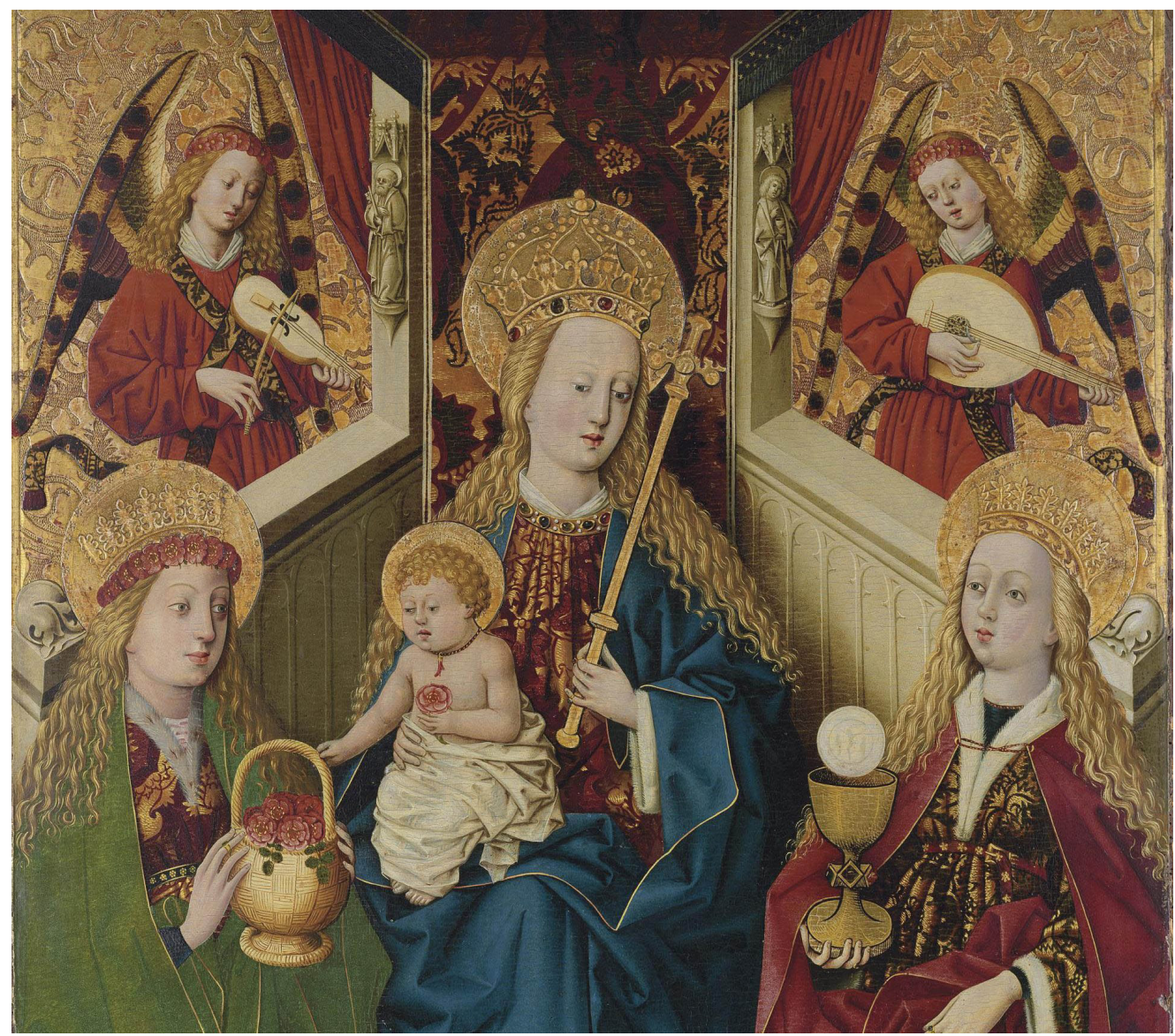

Fuente: Procede posiblemente de la abadía de la Santa Cruz (Austria). Es uno de los centenares de ejemplos de la Virgen rodeada de ángeles tañendo música baja, particularmente con cordófonos. Vendida en Christie's (Londres) en 2012 (fragmento), disponible en https://www.christies.com/lot/lot-the-master-ofthe-pottendorf-votive-panel-5584783/ [Consulta: 10-02-2021]

\subsection{Argumento antropológico}

En el espacio en que se producen los primeros momentos de la crianza no hay varones, salvo José. Y en este espacio de intimidad femenina no puede faltar la música. Al bebé recién nacido hay que calmarlo y dormirlo. San Juan Crisóstomo (siglo IV), en su afán por justificar el uso del canto en la Iglesia, además de hacer notar los muchos beneficios que la música cumplía entre los viajeros, los agricultores o los marineros, añade: "Los cantos poseen tan grande atractivo para nuestra naturaleza que secan las lágrimas, acallan el llanto de los niños de pecho, consiguiendo adormecerlos. Veis, en efecto, que las nodrizas 
que los llevan en brazos se pasean frecuentemente meciéndolos con cantos infantiles, para hacer que cierren sus párpados"28.

Las nanas, efectivamente, son canciones para dormir a las/os niñas/os pequeñas/ os, "suaves melodías cantadas, de trazo simple, de carácter íntimo y de fuerte inspiración amorosa, expuestas individualmente casi siempre por la madre o la abuela"29, pero también son el primer contacto de la criatura neonata con el universo musical que facilita la transición del mundo informe de los sonidos/ruidos en general al universo ordenado y sistematizado de reglas musicales donde se sedimenta una tradición secular que se inocula desde el inconsciente colectivo al individual de cada nuevo miembro de la comunidad.

La presencia de la música baja tañida por ángeles en la escena de la Virgen con Niño remite a este contexto de placidez sonora, sin estridencias, necesario para acometer los primeros años de crianza. El Protoevangelio de Santiago sitúa a santa Ana componiendo un cántico precisamente después de dar de mamar a la Virgen, con palabras exaltan la lactancia: "Su madre la llevó al oratorio de su habitación y le dio el pecho. Entonces compuso un himno al Señor Dios, diciendo: 'Entonaré un cántico al Señor, mi Dios, porque me ha visitado, ha apartado de mí el oprobio de mis enemigos y me ha dado un fruto santo, que es único y múltiple a sus ojos. ¿Quién dará a los hijos de Rubén la noticia de que Ana está amamantando? Oíd, oíd, todas las doce tribus de Israel: Ana está amamantando'”30.

\section{LA VIRGEN Y LOS ÁNGELES QUE TAÑEN MÚSICA BAJA}

El arquetipo cultural del Occidente medieval que vincula a las mujeres con los cordófonos se focaliza en las representaciones marianas en las que la Virgen aparece rodeada de ángeles músicos. Si bien se ha estudiado esta iconografía en tres iconogramas ${ }^{31}$, no se le ha dado a la escena una interpretación comprensiva más allá de la expresión de felicidad y alegría que tal acompañamiento refleja.

Esta profusión del instrumentario no se debe sólo a una manifestación del horror vacui de la plástica bajomedieval ${ }^{32}$. En nuestra opinión, su sustento ideológico último son las arcaicas doctrinas que afirmaban la autonomía de la música, en cuanto a la producción de sentimientos y modelado de caracteres. Indudablemente, el ministerium angelorum imita los coros celestiales y expresa alegría, pero la elección de los instrumentos que los ángeles tañen se encuentra afectada por estas teorías esencialistas que defienden la capacidad de determinación comportamental de los mismos, de las melodías o de los ritmos, y su asociación a determinados estereotipos. Es decir, que las viejas teorías musicales clásicas que atribuían a los diferentes tipos de música instrumental un ethos determinado y generizado se mantienen larvadas o en estado de latencia hasta resurgir al final del siglo XIII con una iconografía bien definida, María con los ángeles músicos, facilitada por el impulso del culto

28 Cit. en Basurco, El canto cristiano..., p. 27.

29 A. Vallejo Cisneros, Música y tradiciones populares, Ciudad Real, Diputación Provincial, 1990, p. 40.

30 Protoevangelio de Santiago, VI.3 (Los Evangelios apócrifos..., p. 62).

31 Principalmente, Virgen con Niño, Coronación y Triunfo de la Virgen: I. Ember, Music in Painting. Music as Symbol in European Renaissance and Baroque, Budapest, Corvina, 1989, pp. 18-19; E. Mâle, El gótico. La iconografía de la Edad Media y sus fuentes, Madrid, Encuentro, 1986, p. 239; G. Cattin, Historia de la música, vol. 2 (primera parte): 'El medioevo'. Madrid, Turner Música, 1979, p. 151. El estudio más completo de este aspecto es el capítulo XI del libro de E. Winternitz, "On Angel Concerts in the 15th Century: A Critical Approach to Realism and Symbolism in Sacred Painting", en B. Brook, E. Downes y S. van Solkema (eds.), Perspectives in Musicology. New York, The Norton Library, 1972, pp. 137-149). Los resultados son una explicación pulcramente musicológica que obvia consideraciones generizadas que son las que aquí se tratan.

32 Como afirma Cattin (Historia de la música..., p. 151) siguiendo a Johan Huizinga. 
a la figura de la Virgen, y específicamente la Virgen con Niño, que no justifica la presencia angélica por el carácter simbólico de lo celestial, pues la escena transcurre en la tierra ${ }^{33}$.

Sin apoyatura bíblica (como en el caso del rey David o de los Veinticuatro Ancianos) debemos preguntarnos el porqué del repetidísimo acompañamiento musical con instrumentos de cuerda, así como la tendencia a representar mayoritariamente cordófonos, cuestiones ajenas a la fidelidad ad litteram.

\section{4. ¿LA PRIMERA REPRESENTACIÓN?: MONASTERIO DE SANTA MARÍA DE CARRACEDO (LEÓN)}

Centraremos la atención en una pequeña y estilizada portada del complejo monástico leonés de Santa María de Carracedo ${ }^{34}$. La estancia en la que se encuentra se adosa a la crujía oriental de la primera planta del claustro y se construyó sobre restos de otra anterior. La tradición la hace parte de un (no demostrado) palacio real, luego "oratorio" del abad (y Jovellanos la conoció como archivo). Se trata de una sala abovedada en la que se abre una portada historiada, la que nos interesa, que comunica con la llamada "Cocina de la reina" (encima de la sala capitular). Esta portada se conforma entre jambas de arista viva que acogen sendas columnas acodilladas, rematadas por capiteles vegetales que sostienen un tímpano y gruesa arquivolta levemente apuntada, elementos ambos profusamente decorados en relieve, guarnecidos por una arcada de medio punto, que articula con otros arcos ciegos el considerado oratorio. Tímpano y arquivolta, en mi opinión, van inextricablemente unidos en la lectura iconográfica (Figura 3).

En el pequeño espacio del tímpano, y adaptadas a la ley del marco, se abigarran quince figuras (cinco han perdido la cabeza, incluida la principal, y otra parcialmente), con un eje ascendente que culmina en el punto axial y simbólico. A tal centro se subordina la estricta simetría del conjunto: doce figuras secundarias se disponen especularmente, apiñadas por alturas, sin dejar un solo espacio libre. Ninguna mira hacia arriba, donde una imagen ambigua, resaltada entre dos espacios sin labrar, sobredimensionada y tocada con una corona, sostiene un personaje infantil en sus brazos. Debajo de ella, también en el centro, impera un personaje tumbado en una cama en la que reclina su hoy desaparecida cabeza. Cruza sus brazos yertos a la altura de la cintura, en posición forzada.

En la única arquivolta se disponen cinco ángeles; uno ocupando la clave del arquito, y los otros cuatro, uno por dovela, flanquean simétricamente al que preside (están decapitados los dos inferiores). Responden todos al mismo modelo, definido por grandes alas, posición sedente sobre sitial cuya base sirve a su vez de doselete al que se encuentra debajo, más la figura axial, representada frontalmente de cintura para arriba. Todos tañen esquemáticas violas de arco apoyadas en el hombro, con caja de resonancia de tendencia piriforme u oval. Los dos únicos clavijeros que se aprecian, romboidales, disponen de tres clavijas.

33 J. Ballester i Gibert, "Els goigs marians i la iconografia musical", Recerca musicológica, IX-X, (1989-1990), p. 371.

34 Sobre los avatares arquitectónicos del monasterio: M. Gómez-Moreno, Catálogo monumental de la provincia de León, Madrid, Ministerio de Instrucción Pública y Bellas Artes, 1925, pp. 406-415; A. M. Martínez Tejera, "Carracedo del Monasterio", en M.Á. García Guinea y J. M. Pérez González (dirs.), Enciclopedia del Románico en Castilla y León. León. Aguilar de Campoo, Fundación Santa María la Real-Centro de Estudios del Románico, 2002, pp. 269-287; S. Mora Alonso-Muñoyerro, "Un monasterio cisterciense en el Bierzo", en Actas del Cuarto Congreso Nacional de Historia de la Construcción, Madrid, Instituto Juan de Herrera, 2005, p. 787; M. Martínez Monedero, Castilla y León y la primera zona monumental (1934-1975). La conservación monumental de Luis Menéndez-Pidal, Salamanca, Junta de Castilla y León, 2011, pp. 178-179; S. Mora Alonso-Muñoyerro y P. Fernández Cueto, "La piel de la cebolla. Superposición de sistemas constructivos en un monasterio cisterciense", en Actas del Octavo Congreso Nacional de Historia de la Construcción, Madrid, Instituto Juan de Herrera, 2013, pp. 703-704. 
Figura 3. Tímpano de Santa María de Carracedo (León)

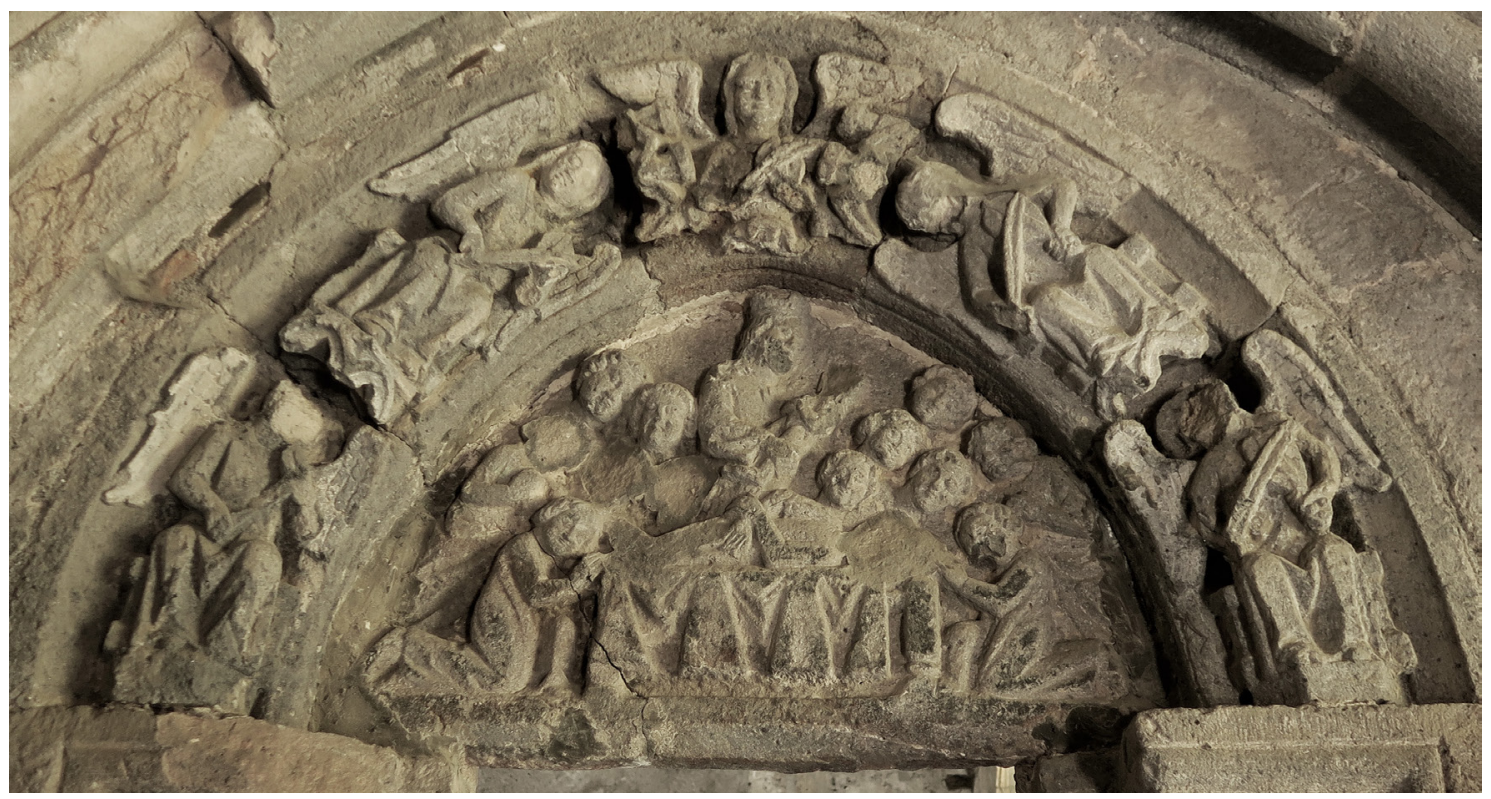

Fuente: fotografía de Jaime Nuño González, a quien le agradezco la cesión para este artículo

Desde el punto de vista técnico se aprecia el deseo de naturalismo (más intención que resultado) en el tratamiento de los paños, marcando los pliegues de la sábana que recubre el lecho donde reposa una figura yacente (casi un altar), o los pliegues en $V$ de las vestiduras angelicales. Se ha intentado además reproducir el rizado de los cabellos de los numerosos rostros que asoman en relieve o las ondas de la melena del personaje que preside el tímpano.

El principal problema de esta escena es su identificación iconográfica. El estado de ruina del monasterio después de la desarmortización, y concretamente de estas estancias, sin techar hasta las campañas de consolidación de Luis Menéndez-Pidal (1948-1963), provocó la destrucción de parte de sus figuras, algunas de ellas en la primera mitad del siglo XX ${ }^{35}$. Afortunadamente, tenemos la fotografía realizada por Manuel Gómez-Moreno en agosto de 1906 (no publicada hasta 1925) ${ }^{36}$, cuando dicha escena se encontraba con sólo dos de sus cabezas perdidas (no cinco y media), y los cinco ángeles intactos (ahora tres). A ella nos remitimos (Figura 4).

Quadrado, a mediados del siglo XIX, sostuvo que la escena "sin duda recuerda la muerte de Veremundo [Vermudo II de León] [...y] representa al monarca tendido en su fúnebre lecho, y sus gentes plañiendo en derredor, y á la reina [Elvira García] teniendo en brazos á su hijo el pequeño Alfonso [ $V$ de León] "37, sumándose a esta lectura el viajero romántico Cáceres Prat ("un precioso relieve, que representa a Bermudo el Gotoso en su lecho de

35 En 1928 solo se había perdido la cabecita del ángel derecho, según vemos en una fotografía de M. Medina (J. M. Luengo, "Una visita al Real monasterio y palacio de Carracedo", ABC, (15 de enero) 1928, p. 17). El resto de las pérdidas, las principales, acaecerían, por tanto, entre esta fecha y el inicio de las intervenciones restauradoras.

36 Gómez-Moreno, Catálogo..., p. 413. @CSIC, Archivo del Centro de Ciencias Humanas y Sociales, ATN/ GMO/a04440). Agradezco la colaboración a Rosa Villalón, Fernando Arce y Raquel Ibáñez (personal de este centro) todas sus facilidades para la reproducción de esta imagen.

37 J. M. Quadrado, Recuerdos y bellezas de España. Asturias y León, Barcelona, Establecimiento tipográficoEditorial de Daniel Cortezo y Ca., 1855, p. 447. 
muerte, rodeado de sus deudos y cortesanos") ${ }^{38}$. Gómez-Moreno, a su vez, la interpretó así: "en la arquivolta, cinco ángeles tocando violines, y en el tímpano, Cristo yacente en un lecho, desnudo y reconocible por sus llagas; en torno once (sic) hombres adorando, que serán los Apóstoles, y entre ellos la Virgen María coronada, teniendo en sus brazos el alma, en forma de niño desnudo". No obstante, el insigne erudito reconoció la turbación que le producía la escena y confesó: "Nunca he visto otra representación así; mas, aunque parezca disparatada, guarda paralelismo con las usuales en los sepulcros, habiendo de buscársele un sentido místico, ya que no histórico"39. José María Luengo califica la escena de "joya escultórica del palacio" pero, evasivo, resume: "Sobre dos columnas susténtase el arco, adornado de ángeles, bajo doseletes, tañendo violas, y en el tímpano descuella una escena macabra, cuyo significado ha tenido muy distintas interpretaciones" ${ }^{\prime \prime}$. En nuestros días, Martínez Tejera entendió que “...se representa a la Virgen muerta rodeada por los doce apóstoles y una arquivolta decorada con ángeles músicos”41.

Figura 4. La portada estudiada de Carracedo, según la fotografió Gómez-Moreno en 1906, antes de la destrucción parcial de algunos relieves

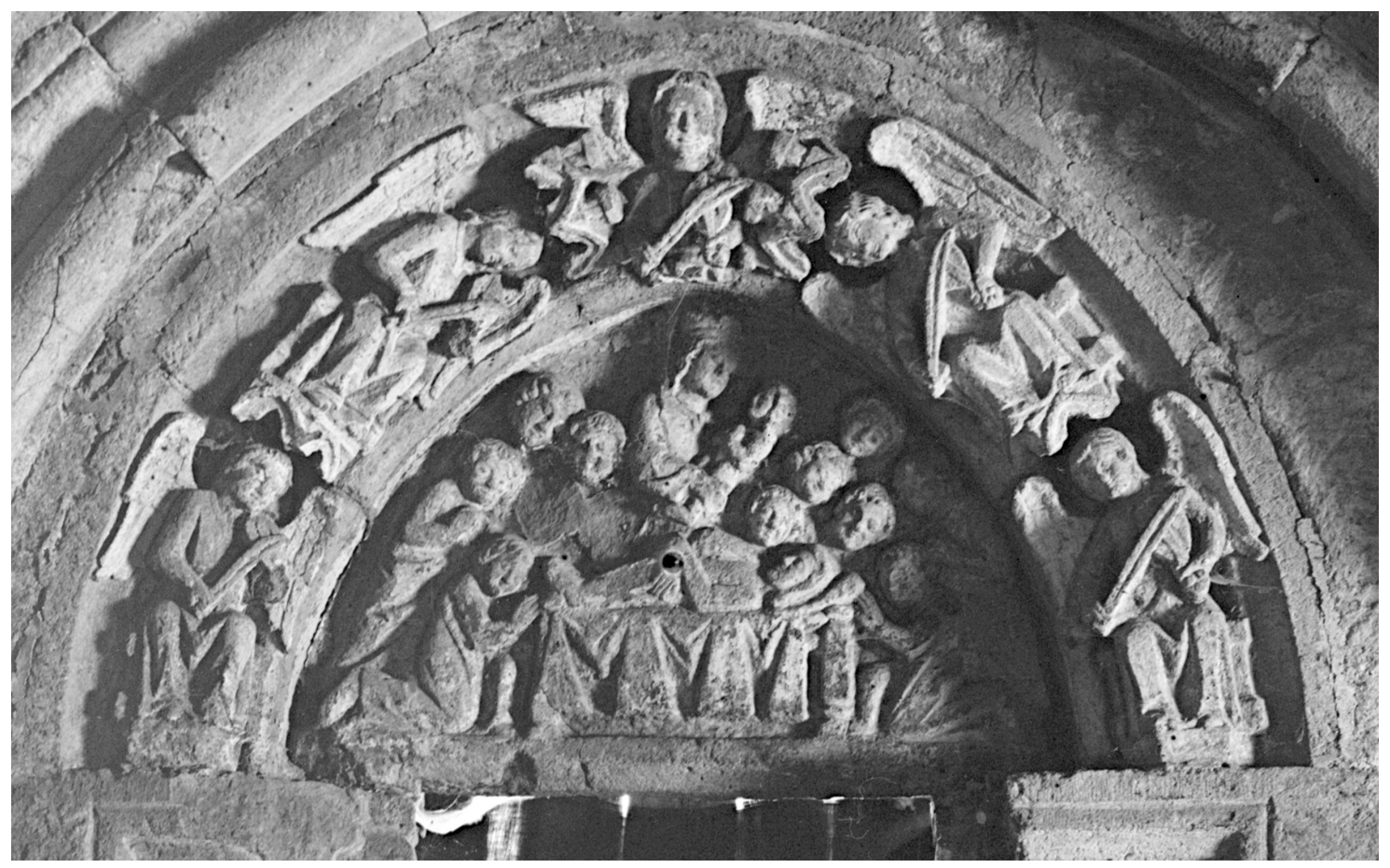

Fuente: (CCSIC, ACCHS, ATN/GMO/a04440 (detalle)

En nuestra opinión, el motivo elegido es una variante peculiar de la Dormición de la Virgen, la Koimesis del arte bizantino. La presencia de los Doce apóstoles (con el convencionalismo de los genuflexos en los extremos) aconseja descartar que se trate de un túmulo regio, como pensaban en el siglo XIX. Además de que sería insólita la ubicación en un tímpano, a ningún rey se le representaría ante el Colegio apostólico.

38 A. Cáceres Prat, El Vierzo. Su descripción é historia, León, Ediciones leonesas, 1883, reed. facs. 1992, p. 90.

39 Gómez-Moreno, Catálogo..., p. 413.

40 Luengo, "Una visita al Real monasterio", p. 17.

41 Martínez Tejera, "Carracedo del Monasterio", p. 279. 
Las fuentes escriturísticas de donde se extrae el entorno narrativo de esta escena son extracanónicas, pues de la muerte de María nada se dice en los escritos neotestamentarios. Sí en los Evangelios apócrifos asuncionistas, como en el libro de san Juan Evangelista el Teólogo (siglo IV), el de Juan, arzobispo de Tesalónica (ca. siglo IV) y en la más tardía narración del Pseudo José de Arimatea.

El escultor, con más documentación que maña, conocía al menos parcialmente los elementos fundamentales del relato y la tradición iconográfica occidental de este motivo, no demasiado frecuente en tiempos románicos: María situada en una cama paralela a la parte baja de la composición rodeada de los discípulos de Jesús (isocéfalos y con dos de ellos, Pedro y Pablo, delimitando el lecho, pero sin individualizarse, como ocurre en Oriente), la entrega del alma antropomorfa, la ausencia de mobiliario, y la presencia de ángeles.

La interpretación de la rosca de la arquivolta de Carracedo no ofrece duda, y representa el cielo que rodea la escena terrenal. Según el relato apócrifo: "a la vez que el resplandor empezó a retirarse, dio comienzo la asunción al cielo del alma de la bienaventurada virgen María entre salmodias, himnos y los ecos del Cantar de los Cantares" ${ }^{42}$. Ese ubi celestial es habitado por ángeles sorprendidos en plena ejecución instrumental conjunta, en lo que debe ser una de las primeras apariciones de esta guisa desde las cohortes corales de los Ancianos de los Beatos.

La antropomorfización del alma ascendente responde también a la letra del relato apócrifo, si bien este recurso no era desconocido en la escultura funeraria románica en un contexto relativamente cercano a Carracedo, como se ve en el magnífico sepulcro de una dama desconocida que se halla en la iglesia zamorana de la Magdalena (ca. 1190), en su día iglesia de la orden del Hospital. El alma de la difunta, también corporeizada, se muestra envuelta en un paño que sostienen dos ángeles pero, al no tratarse de escena hierofánica, sino de mujer terrenal, sin atisbo musical alguno. (Fig. 5)

Figura 5. Relieve del sepulcro femenino de la iglesia de La Magdalena, Zamora. Ascensión del alma (representada de medio cuerpo) entre ángeles. Otros dos ángeles turiferarios flanquean la escena

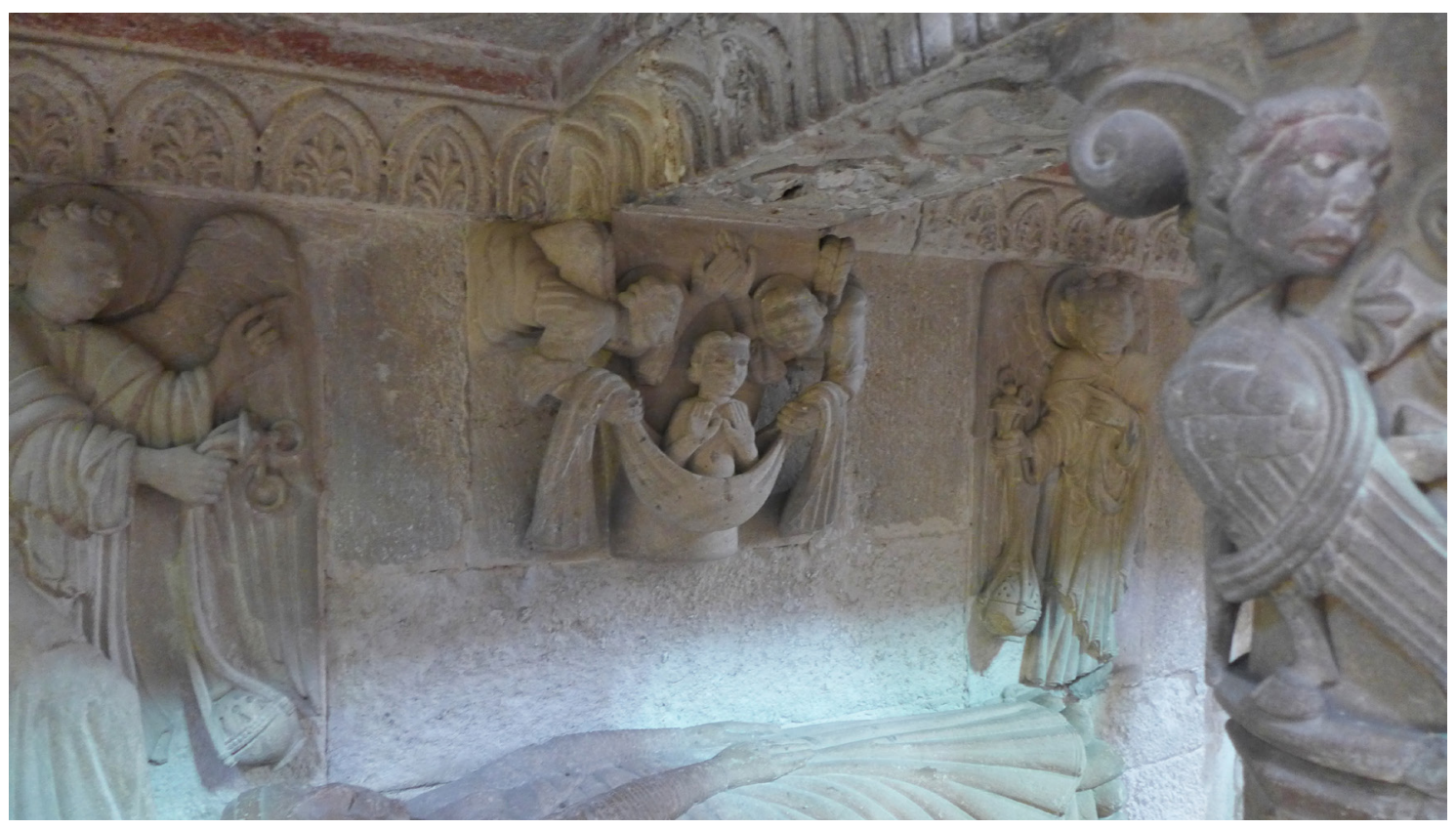

Fuente: fotografía del autor

42 Narración del Pseudo José de Arimatea, XII (Los Evangelios apócrifos..., p. 347). 
No se nos escapa que la figura que sostiene el personaje coronado más que alma parece Niño, por la presencia de cuerpo entero, por aparecer sin fajar, y por la mirada (hoy también destruida) que le dirige a la Madre. No obstante, las manos en actitud de oración serán características llamadas a perdurar en la representación de la ascensión del anima en la escultura monumental leonesa de contextos funerarios ${ }^{43}$, y no son propias del Niño.

La identificación de la figura erguida y coronada, centro de la escena, es sin duda femenina, como se aprecia en la imagen antes de la destrucción parcial de su faz, diferenciada de las demás, y con visible melena. Ha de ser María, pues mantiene la misma actitud hacia quien sostiene con la que sus homólogas góticas de talla se relacionaban con el Hijo. Pero, a tenor de lo dispuesto en el relato apócrifo, esta figura debía ser la de Cristo, pues Éste le dijo a la Madre: "cuando me vieres venir a tu encuentro en compañía de los ángeles y de los arcángeles, de los santos, de las vírgenes y de mis discípulos, ten por cierto entonces que ha llegado el momento en que tu alma va a ser separada del cuerpo y trasladada por mí al cielo". Efectivamente: "Llegado el domingo, y a la hora de tercia, bajó Cristo acompañado de multitud de ángeles, de la misma manera que había descendido el Espíritu Santo sobre los apóstoles en una nube, y recibió el alma de su madre querida. Y mientras los ángeles entonaban el pasaje aquel del Cantar de los Cantares"44.

Se aleja la Dormición de Carracedo, pues, de convencionalismos importantes como la representación del anima, la falta de cendal en que envolverla, o la ausencia del arcángel Miguel (o una mano, en su defecto) que acuda a recogerla para transportarla al cielo. El esquematismo de esta escena y su discreción formal puede explicar en parte estas faltas, pero tampoco se puede asegurar que la pérdida de policromía que hubo de revestir la escena no completase los detalles no labrados. En suma, la escena estaría en consonancia con "la simplicidad estructural, la concisión narrativa y la austeridad eidética típicas de las dormiciones occidentales" 45 . No cuadra, de ninguna manera, la ausencia de Cristo. Resta, además, la duda, sobre la identidad del personaje yacente. Más que cabellos, parecen almohadas en las que apoya la cabeza, o una almohada y un velo. Ningún atributo sexuado parece identificarle. Si no es María, se hace difícil pensar en otro candidato. No se puede descartar la intuición de Gómez-Moreno (Cristo yacente), pero ni vemos, como afirmó él, sus llagas, ni tendría sentido el resto de la escena. Cristo no murió rodeado del Colegio apostólico. Sería un unicum.

Las concomitancias del resto de elementos de la escena con los otros de la Dormición y, añadimos, la inclusión de los ángeles tañendo violas de arco, instrumentario llamado a acompañar a la Virgen pocas décadas después de labrarse esta portada, aconsejan esta hipótesis, que también no sitúa ante la incómoda calificación de unicum, pero con menos elementos discordantes que si se tratase de Cristo. Así, en la misma escena María aparece muerta y portando su alma (por eso podrá tocarla sin cendal) pero con la fusión y mistificación de dos escenas: la Dormición y la Virgen con Niño, en una suerte de desdoblamiento iconográfico.

El gótico, por su parte, recogerá con profusión la Dormición, particularmente formando parte de la escultura monumental catedralicia o grandes iglesias. De ellas destacamos la incluida en el dintel de la portada sur del transepto de la seo de El Burgo de Osma (Soria), catedral advocada a la Asunción de la Virgen. En esta portada, levantada hacia 1280, y

43 Así aparecen en los sepulcros de Miguel Domínguez (ca. 1335) y de Juan Martínez (ca. 1392) en la catedral de León.

44 Narración del Pseudo José de Arimatea, II y XI-XII (Los Evangelios apócrifos..., pp. 344 y 347). Sobre este motivo: S. González, José María, "Iconografía de La Dormición de la Virgen en los siglos X-XII. Análisis a partir de sus fuentes legendarias", Anales de Historia del Arte, 21 (2011), pp. 9-52.

45 S. González, "Iconografía de La Dormición”, p. 49. 
de mayor calidad técnica que el tímpano carracetense, una de las cuatro arquivoltas que la enmarcan contiene catorce músicos ${ }^{46}$. Es planteable la duda de si tales instrumentistas ponían fondo sonoro a la ascensión del alma virginal (pero no son alados), o si formaban conjunto con la (perdida) escena pintada del tímpano, dedicada al Juicio Final, y por tanto fueran una parcial representación de los Veinticuatro Ancianos (Figura 6).

Figura 6. Dormición de la Virgen con el alma antropomorfa en forma de busto en actitud orante. Dintel de la portada sur del transepto de la catedral de El Burgo de Osma (Soria)

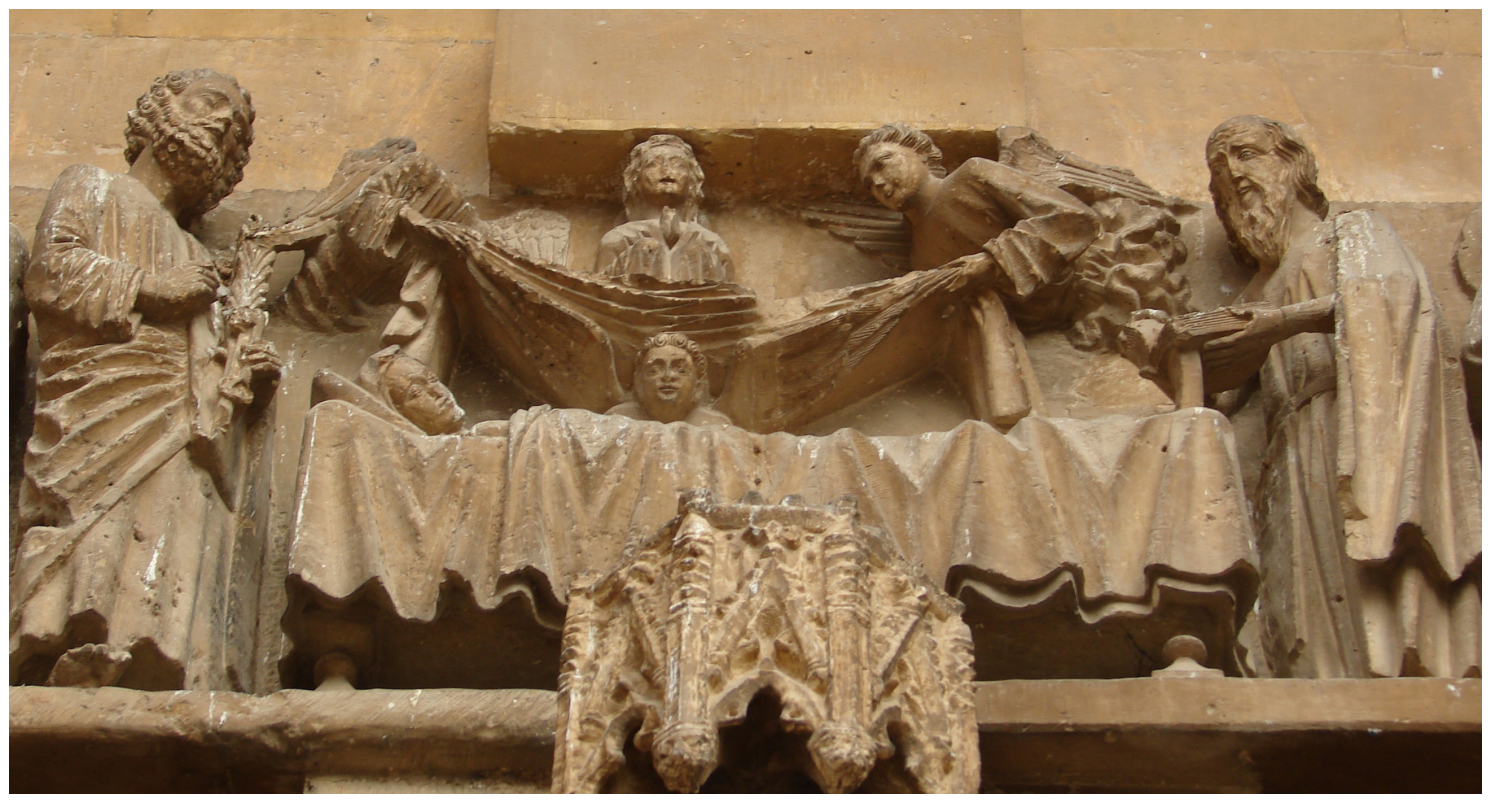

Fuente: fotografía del autor

No es sencillo fechar con precisión la escena carracetense. La complejidad de la presunta "Cocina de la Reina", a la que esta portada da acceso, es grande. Posiblemente fue elevada en altura ya en el siglo XIII (de hecho, los escalones arrancan desde el propio umbral de la portada), lo que podría valer para fechar el tímpano ante quem, pues parece que se abrió sobre una construcción previa (un presunto palacio real). Ciertamente, no es fácil retrasar mucho más esta cronología, ni por estilo, ni por argumento iconográfico, pues la Virgen comienza a representarse con profusión en Occidente desde el siglo XII, merced al impulso devocional que los cistercienses hacen de su figura o, mejor, de algunos de sus atributos. Habitaban monjes blancos en Carracedo cuando se labró este tímpano de insistente presencia mariana, si bien fueron todavía benedictinos quienes cambiaron la advocación del monasterio de San Salvador a Santa María al menos desde 1152 y comenzaron un periodo de expansión floreciente. Venía de antiguo, pues, la devoción mariana en el cenobio. En algún momento del siguiente siglo, por tanto, debió labrarse este conjunto iconográfico: "obra gótica, de la mitad del siglo XIII", sentenció Gómez-Moreno ${ }^{47}$. Como centro de poder que fue Carracedo, este estilo debió llegar temprano, simultáneamente a cuando lo hacía en el reino de León, al que pertenecía ${ }^{48}$.

46 Un análisis del origen y paralelos góticos de esta portada en J.-M. Martínez Frías, El gótico en Soria. Arquitectura y escultura monumental, Salamanca, Universidad de Salamanca, 1980, pp. 99-125.

47 Gómez-Moreno, Catálogo..., p. 413.

48 En un reciente artículo se demuestra el conocimiento de la escultura monumental románica francesa de 


\section{CONCLUSIONES}

Sin los condicionantes impuestos por el sistema patriarcal, que impuso distintas prácticas musicales en función del sexo, y asoció diferentes instrumentos musicales para los varones y las mujeres de carne y hueso, la asociación Virgen con ángeles músicos no habría llegado a materializarse de este modo. Por ello, la abundancia de instrumentos propios de la música baja. La presencia en una escena mariana (sea la que fuere) de cinco ángeles músicos tañendo violas de arco en el tímpano de Santa María de Carracedo adelanta la cronología de este contexto iconográfico en varias décadas, según lo que tradicionalmente mantenían los estudios de iconografía musical, no solo en el contexto hispano, sino también en el europeo.

\section{BIBLIOGRAFÍA}

Andrés, R., "Anotaciones para un prólogo", [Prólogo a] Los luthiers españoles (de Ramón Pinto Comas). Barcelona, 1988.

Ballester i Gibert, J., "Els goigs marians i la iconografia musical", Recerca musicológica, IX-X (1989-1990), pp. 367-372.

- "Retablos tardomedievales con ángeles músicos procedentes del antiguo Reino de Aragón. Catálogo", Revista de Musicología, 12/1 (1990), pp. 123-201.

- "Music in the Sixteenth-Century Catalan Painting", Music in Art (2006), pp. 132-142.

Barral Rivadulla, M. D., "Ángeles y demonios, sus iconografías en el arte medieval", Cuadernos del CEMYR, 11 (2003), pp. 211-235.

Basurco, F. J., El canto cristiano en la tradición primitiva, Madrid, Ediciones Marova, 1966.

Bowles, E. A., La pratique musicale au Moyen Age. Musical Performance in the Late Middle Ages, Géneve, Minkoff \& Lattès, 1983.

Boydell, B., "Female Figures on Irish and European Harps", The Galpin Society Journal, 50 (1997), pp. 306-306.

Buckley, A., "Musical Instruments in Ireland from the Ninth to the Fourteen Centuries. A review of the Organological Evidence", Irish Musical Studies, 1 (1990), pp. 13-57.

Cabezón, A. de, Obras de Música para tecla, arpa y vihuela... recopiladas y puestas en cifra por Hernando de Cabezón su hijo (Madrid 1578), vol. I. Higinio Anglés (ed.), Barcelona, CSIC, 1982.

Cáceres Prat, A., El Vierzo. Su descripción é historia, León, Ediciones leonesas, 1883, reed. facs. 1992.

Cattin, G., Historia de la música, vol. 2 (primera parte): 'El medioevo'. Madrid, Turner Música, 1979.

Las Edades del hombre. La música en la iglesia de Castilla y León, Valladolid, 1991.

Ember, I., Music in Painting. Music as Symbol in European Renaissance and Baroque Painting, Budapest, Corvina, 1989.

Franco Mata, Á., Escultura gótica en León y su provincia, Salamanca, Instituto Leonés de Cultura, 1998.

Franco-Lao, M., Música bruja. La mujer en la Música, Barcelona, Icaria, 1980.

Fubini, E., La estética musical desde la Antigüedad hasta el siglo XX, Madrid, Alianza, 1997.

vanguardia en intervenciones en el monasterio (J. A. Moráis Morán y M. C. Cosmen Alonso, "La desaparecida portada románica del monasterio de Santa María de Carracedo (León)", Anuario de Estudios Medievales, 50/1, (2020), pp. 249-254). Poco después se comenzaba a levantar el programa iconográfico gótico de la catedral de León, con la imagen de la Virgen erguida con Niño, la Virgen Blanca (1275-1285), en el parteluz de la portada central del pórtico occidental (A. Franco Mata, Escultura gótica en León y su provincia, Salamanca, Instituto Leonés de Cultura, 1998, p. 362). 
Gelineau, J., Canto y música en el culto cristiano, Madrid, Juan Flors, editor, 1967.

Ghisi, F., "Angeli musicanti in una tavola attribuita al Giottino nel Museo del Bargello di Firenze", en F. Gallo (ed.), L'ars nova italiana del Trecento, Certaldo, Centro di Studi sull'Ars Nova italiana del Trecento, 1968, pp. 91-96.

Gillette, A., "Depicting the Sound of Silence: Angels' Music and Angelization in Medieval Sacred Art", Imago Musicae, 27/28 (2014/2015), pp. 95-125.

- "The Music of Angels in Byzantine and Post-Byzantine Art", Peregrinations. Journal of Medieval Art and Architecture, 6/4 (2018), pp. 26-78.

Gómez-Moreno, M., Catálogo monumental de la provincia de León, Madrid, Ministerio de Instrucción Pública y Bellas Artes, 1925.

Kartomi, M. J., On Concepts and Classifications of Musical Instruments, Chicago and London, The University of Chicago Press, 1990.

Lorenzo Arribas, J., Las mujeres y la música en la Edad Media europea: relaciones y significados, Madrid, Universidad Complutense, Tesis doctoral inédita, 2004.

- "La voz femenina, un tabú cultural. Mujeres, música y representaciones en el Románico", en Féminas: el protagonismo de la mujer en los siglos del románico. Aguilar de Campoo, Fundación Santa María la Real, 2020, pp. 189-225.

Luengo, J. M., "Una visita al Real monasterio y palacio de Carracedo", $A B C$, (15 de enero) 1928, pp. 16-18.

Mâle, E., El gótico. La iconografía de la Edad Media y sus fuentes, Madrid, Encuentro, 1986. Martínez Frías, J. M., El gótico en Soria. Arquitectura y escultura monumental, Salamanca, Universidad de Salamanca, 1980.

Martínez Monedero, M., Castilla y León y la primera zona monumental (1934-1975). La conservación monumental de Luis Menéndez-Pidal, Salamanca, Junta de Castilla y León, 2011.

Martínez Tejera, A. M., "Carracedo del Monasterio”, en M. Á. García Guinea y J. M. Pérez González (dirs.), Enciclopedia del Románico en Castilla y León. León, Aguilar de Campoo, Fundación Santa María la Real-Centro de Estudios del Románico, 2002, pp. 269-287.

Meyer-Baer, K., Der chorische Gesang der Frauen mit besonderer Bezugnahme seiner Betätigung auf geistlichem Gebeit, Leipzig, Breitkopf und Härtel, 1917.

Montagu, J. y G., Minstrels and Angels Carvings of Musicians in Medieval English Churches, Berkeley, Fallen Lean Press, 1998.

Mora Alonso-Muñoyerro, S., "Un monasterio cisterciense en el Bierzo", en Actas del Cuarto Congreso Nacional de Historia de la Construcción, Madrid, Instituto Juan de Herrera, 2005, pp. 781-789.

Mora Alonso-Muñoyerro, S. y Fernández Cueto, P., "La piel de la cebolla. Superposición de sistemas constructivos en un monasterio cisterciense", en Actas del Octavo Congreso Nacional de Historia de la Construcción, Madrid, Instituto Juan de Herrera, 2013, pp. 699-705.

Moráis Morán, J. A. y Cosmen Alonso, M. C., "La desaparecida portada románica del monasterio de Santa María de Carracedo (León)", Anuario de Estudios Medievales, 50/1 (2020), pp. 231-266.

Mudarra, A., Tres libros de música en cifras para vihuela. Sevilla, Juan de León, 1546.

Narváez, L. de, Los seys libros del Delphín de música, Valladolid, 1538.

Perpiñá García, C., "Los ángeles músicos en el tipo iconográfico de la Anunciación", en Emblemática trascendente: hermenéutica de la imagen, iconología del texto. Pamplona, Universidad de Navarra, 2011, pp. 673-687.

- "Los ángeles músicos. Estudio de los tipos iconográficos de la narración evangélica", 
Anales de Historia del Arte (vol. extraord., 2011), pp. 397-411.

- "Música angélica en la imagen mariana. Un discurso visual sobre la esperanza de salvación", Acta Artis. Estudis d'Art Modern, 1 (2013), pp. 29-49.

Pugh, A., Women in Music, Great Britain, Cambridge University Press, 1991.

Quadrado, J. M., Recuerdos y bellezas de España. Asturias y León, Barcelona, Establecimiento tipográfico-Editorial de Daniel Cortezo y Ca., 1885.

Rieger, E., “¿‘Dolce semplice’? El papel de las mujeres en la música”, G. Ecker (ed.), Estética feminista, Barcelona, Icaria, 1986, pp. 175-196.

Rodríguez Suso, M. C., "The Nursing Madonna with Musical Angels in the Iconography", Music in Art, 12/1 (1987), pp. 11-19.

- "Un ejemplo de iconología musical: María Lactans y los ángeles en la Cataluña bajomedieval”, Cuadernos de Sección. Música, 4 (1988), pp. 7- 34.

Sachs, C., Historia universal de los instrumentos musicales, Buenos Aires, Ediciones Centurión, 1947.

Salmen, W., "The Social Status of the Musician in the Middle Ages", en Walter Salmen (ed.), The Social Status of the Professional Musician from the Middle Ages to the 19th Century, New York, Pendragon Press, 1983, pp. 3-29.

Salvador González, J. M., "Iconografía de La Dormición de la Virgen en los siglos X-XII. Análisis a partir de sus fuentes legendarias", Anales de Historia del Arte, 21 (2011), pp. 9-52.

Salvador González, J. M. y Perpiñá García, C., "Exaltata super choros angelorum: Musical Elements in the Iconography of the Coronation of the Virgin in the Italian Trecento Painting", Music in Art, 39/1-2 (2014), pp. 61-86.

Santos Otero, A. de (ed.), Los Evangelios apócrifos, Madrid, Biblioteca de Autores Cristianos, 2005.

Schneider, M., El origen musical de los animales-símbolos en la mitología y la escultura antiguas, Madrid, CSIC, 1946.

Vallejo Cisneros, A., Música y tradiciones populares, Ciudad Real, Diputación Provincial, 1990.

Waddell, H., The Wandering Scholars, London, Constable, 1966.

Winternitz, E., "On Angel Concerts in the 15th Century: A Critical Approach to Realism and Symbolism in Sacred Painting", en B. Brook, E. Downes y S. van Solkema (eds.), Perspectives in Musicology, New York, The Norton Library, 1972, pp. 137-149.

- Musical Instruments and Their Symbolism in Western Art, New Haven and London, Yale University Press, 1979. 